\title{
Radiological Outcome of Fracture of Neck-of-Femur Treated with Two versus Three Cannulated Screws Fixation in Adults
}

Muhammad Usman Khalid, Muhammad Waqas, Muhammad Akhtar, Rana Dilawaiz Nadeem, Muhammad Bilal Javed, Syed Faraz UI Hassan Shah Gillani

Department of Orthopedic Surgery and Traumatology, King Edward Medical University, Mayo Hospital, Lahore, Pakistan

\begin{abstract}
Objective: To compare the radiological outcome of two cannulated screws versus three cannulated screws in fixation of fractures of neck-of-femur in adults.

Study Design: An experimental study.

Place and Duration of Study: Department of Orthopedic Surgery and Traumatology, Mayo Hospital, Lahore from September 2013 to September 2015.

Methodology: A total of one hundred and twenty adults, age ranging from 14-49 years, with all Garden's types fracture of neck-of-femur, were inducted through Accident \& Emergency Department after a written informed consent. Patients were randomly divided into two treatment groups. Group A underwent two cannulated screws fixation, while Group B underwent three cannulated screws fixation. Radiological union was checked at the 12th postoperative week.

Results: The median age was 36 years with interquartile range of $1.5(\mathrm{p}=0.895)$. There were $54(90 \%)$ males and 06 $(10 \%)$ females in GroupA; while $55(91.7 \%)$ males and $05(8.3 \%)$ females in Group-B ( $p=0.752)$. In the $12^{\text {th }}$ postoperative week, radiological union was evident in $107(89.2 \%)$ patients. The frequency of radiological union at $12^{\text {th }}$ postoperative week was $98.3 \%$ in Group A and $80.0 \%$ in Group B ( $p<0.001)$.

Conclusion: Frequency of radiological union of two cannulated screws fixation was found to be significantly higher than three cannulated screws fixation in adults with fracture of neck-of-femur.
\end{abstract}

Key Words: Fracture of neck-of-femur, Radiological union, Cannulated screws, RUSH score.

How to cite this article: Khalid MU, Waqas M, Akhtar M, Nadeem RD, Javed MB, Gillani SFUHS. Radiological outcome of fracture of neck-of-femur treated with two versus three cannulated screws fixation in adults. J Coll Physicians Surg Pak 2019; 29(11):1062-6.

\section{INTRODUCTION}

Fractures of neck-of-femur in adults are infrequent with estimated incidence of 1.7 million in 1990 to 6.3 million by $2050.1,2$ These fractures often occur due to high energy trauma. ${ }^{3}$ Moreover, these fractures have high association with osteonecrosis of femoral head and nonunion. Various factors can play important role in preventing these horrible complications and impart in better outcomes. ${ }^{3}$ Achieving anatomical reduction and accurate internal fixation are mandatory. Other treatment variables, included surgery time, the role of capsuolotomy and the methods of fixation remain questionable. ${ }^{3,4}$ Treatment goals of fracture of neck-of-femur include prompt, early diagnosis, timely surgery, anatomical reduction, decompression of capsule and stable internal fixation. ${ }^{5}$

Correspondence to: Dr. Muhammad Usman Khalid, Department of Orthopedics Surgery and Traumatology,

King Edward Medical University, Mayo Hospital, Lahore,

Pakistan.

E-mail: ukkazi179@gmail.com

Received: September 09, 2017; Revised: July 11, 2019;

Accepted: August 23, 2019
Per Xarchas used only two cannulated screws and reported that $12(60 \%)$ patients returned to their previous occupation and daily activities of life. There were no complications in any of the patients and $100 \%$ union rate was achieved. 6 Chen et al. compared DHS and three cannulated screws, which resulted in $100 \%$ union rate in cannulated group with three screws and $89.29 \%$ union in DHS group, showing no significant difference $(p>0.05) .{ }^{7}$

A local study using three cannulated screws in middleaged patients reported $9(36 \%)$ patients had complications. Of which, $3(12 \%)$ had avascular necrosis, $4(16 \%)$ had non-union, union (84\%), and $2(8 \%)$ patients had implant loosening. ${ }^{8}$

Conventionally, three cannulated screws are used for the treatment of femoral neck fractures in adults to provide relative strength of fixation in these fractures to achieve union. The relative strength and union can be achieved using two screws in such fractures. No local data was available on two versus three cannulated screws for the fracture of neck-of-femur; while internal data was available, which was not enough to support the scientific evidence to the treatment. 
The aim of this study was to evaluate treatment outcome in terms of radiological evidence of radiological union in two versus three cannulated screws for fixation of fracture of neck-of-femur in young adults.

\section{METHODOLOGY}

This experimental study was conducted, using probability simple random sampling techniques, at the Accident \& Emergency Department of Orthopedic Surgery and Traumatology, King Edward Medical University, Mayo Hospital, Lahore from September 2013 to September 2015. A total of 120 cases were randomly divided into Group $A$ and Group B, using lottery method. Patients of both genders, with age ranging from 14-49 years, were inducted through Accident \& Emergency Department of Orthopedic Surgery, who had Garden type I, II, III and IV fractures of neck-of-femur and had presented within 24 hours of the injury diagnosed on history, clinical examination and conventional radiographs (Figure 1). Patients with metabolic bone disease evident on clinical and biochemical investigations, clinical presentation and medical record of skeletal dystrophy or congenital anomaly (on clinical examination), bone malignancy and presenting with multiple fractures, were excluded from the study.

Approval from Hospital Ethical Committee was obtained. All the procedures of fixation were explained to the patients before surgery. After taking informed consent from the patients, demographic profile (name, age, gender) was noted. All patients were temporarily immobilised using skin traction with hanging weight of approximately 4-5 pounds. Group A patients were treated with two cannulated screws and Group B patients were treated with three cannulated screws. Patients were placed on traction table and fractures were reduced using Ledbetter technique. Later, the reduction was confirmed on image intensifier. All cases were operated with closed reduction, using cannulated stainless steel $6.5 \mathrm{~mm}$ cancellous screws with $16 \mathrm{~mm}$ thread size, using image intensifier. The length of the screws was measured peroperatively as required. Then surgery was done under general anesthesia by a single surgical team of consultants and trainees.

Quadricep exercises were started on the third postoperative day. Upon follow-up, patients were taught quadricep exercises and knee bending exercises. Radiological progression of the union was assessed using radiological union score for the hip (RUSH). It assesses radiographic union in two orthogonal views using the index of cortical bridging, cortical appearance. It utilised four components of scores as cortical bridging, cortical disappearance, trabecular consolidation and trabecular disappearance. Cortical bridging has score range from 4 to 12 . It can be determined by scoring each of four cortices from 1 to 3 as no cortical bridging, some cortical bridging and complete cortical bridging, respectively.
Cortical bridging was defined as consolidation and evidence of new bone formation between and around the fracture. Cortical disappearance also has 4 to 12 score range and it based on visibility of the fracture line on four cortices on radiographs. It has 1 as fracture line fully visible, 2 some evidence of fracture line, and 3 has no evidence of fracture line. Two trabecular indices were scored from 1 to 3 . It is based on the consolidation for one of the indices and fracture line disappearance for the other. Trabecular index of consolidation is scored as 1 , some evidence of consolidation is scored as 2, and complete evidence of consolidation is scored as 3 . The cortical index of fracture line disappearance was taken as 2 and no evidence of fracture line as score 3.9 Partial weight bearing was started at $4^{\text {th }}$ week and full weight bearing was allowed at $8^{\text {th }}$ week postoperatively. All the patients in both Groups were followed for radiological union in outpatient department. All the data was noted on proforma at $3^{\text {rd }}, 6^{\text {th }}, 9^{\text {th }}$ and $12^{\text {th }}$ weeks post-operatively.

All the collected data were analysed by SPSS Version 20. Numerical variables like age has been presented as median with interquartile value, and data compared by Mann-Whitney U-test. Categorical variables, i.e. gender and radiological union have been presented by frequency and percentage. Chi-square test has been applied to compare radiological union in both the study groups, taking $p$-value $\leq 0.05$ as significant.

\section{RESULTS}

This study involved 120 patients with neck-of-femur fractures. The age of the patients ranged from 14 years to 49 years. The median age was 36 years with interquartile range as $1.5(p=0.895)$. Majority $(n=109,90.8 \%)$ of the patients were males, while only $11(9.2 \%)$ were females.

These patients were divided into two treatment groups after randomisation. Group A comprising of 60 patients were treated by two cannulated screws; and Group B comprising of 60 patients underwent three cannulated screws. Similarly, there were $54(90 \%)$ males and 06 $(10 \%)$ females in Group A; while $55(91.7 \%)$ males and $5(8.3 \%)$ females in Group B, yet the difference between the two groups was statistically insignificant $(p=0.752)$.

There was no radiological union of any case on followup at $3^{\text {rd }}$ and 6th postoperative weeks. Only 11 (9.2\%) patients showed radiological union on 9th postoperative week; comprising of $8(13.3 \%)$ patients among Group A and $3(5 \%)$ patients among Group B. When compared between the two groups, this difference was statistically insignificant $(p=0.114)$, as shown in Table I.

On $12^{\text {th }}$ postoperative week, radiological union was evident in $107(89.2 \%)$ patients. The frequency of radiological union at $12^{\text {th }}$ postoperative week was $98.3 \%$ in Group A (Figure 2) and $80.0 \%$ in Group B (Figure 3). This difference was statistically significant $(p<0.001)$ as shown in Table II. 
Table I: Comparison of radiological union between the two study groups at 9 weeks.

\begin{tabular}{|c|c|c|c|c|}
\hline & \multicolumn{2}{|c|}{ Radiological union: 9 weeks } & \multirow[t]{2}{*}{ Total } & \multirow[t]{2}{*}{$p$-value } \\
\hline & Yes & No & & \\
\hline \multicolumn{5}{|l|}{ Study group } \\
\hline Group-A count & 8 & 52 & 60 & 0.114 \\
\hline$\%$ within study group & $13.3 \%$ & $86.7 \%$ & $100.0 \%$ & \\
\hline Group-B count & 3 & 57 & 60 & \\
\hline$\%$ within study group & $5.0 \%$ & $95.0 \%$ & $100.0 \%$ & \\
\hline \multicolumn{5}{|l|}{ Total } \\
\hline Count & 11 & 109 & 120 & \\
\hline$\%$ within study group & $9.2 \%$ & $90.8 \%$ & $100.0 \%$ & \\
\hline
\end{tabular}

Table II: Comparison of radiological union between the two study groups at 12 weeks.

\begin{tabular}{|c|c|c|c|c|}
\hline & \multicolumn{2}{|c|}{ Radiological union: 12 weeks } & \multirow[t]{2}{*}{ Total } & \multirow[t]{2}{*}{$\mathrm{p}$-value } \\
\hline & Yes & No & & \\
\hline \multicolumn{5}{|l|}{ Study group } \\
\hline Group-A count & 59 & 1 & 60 & $<0.001$ \\
\hline$\%$ within study group & $98.3 \%$ & $1.7 \%$ & $100.0 \%$ & \\
\hline Group-B count & 48 & 12 & 60 & \\
\hline$\%$ within study group & $80.0 \%$ & $20.0 \%$ & $100.0 \%$ & \\
\hline \multicolumn{5}{|l|}{ Total } \\
\hline Count & 107 & 13 & 120 & \\
\hline$\%$ within study group & $89.2 \%$ & $10.8 \%$ & $100.0 \%$ & \\
\hline
\end{tabular}

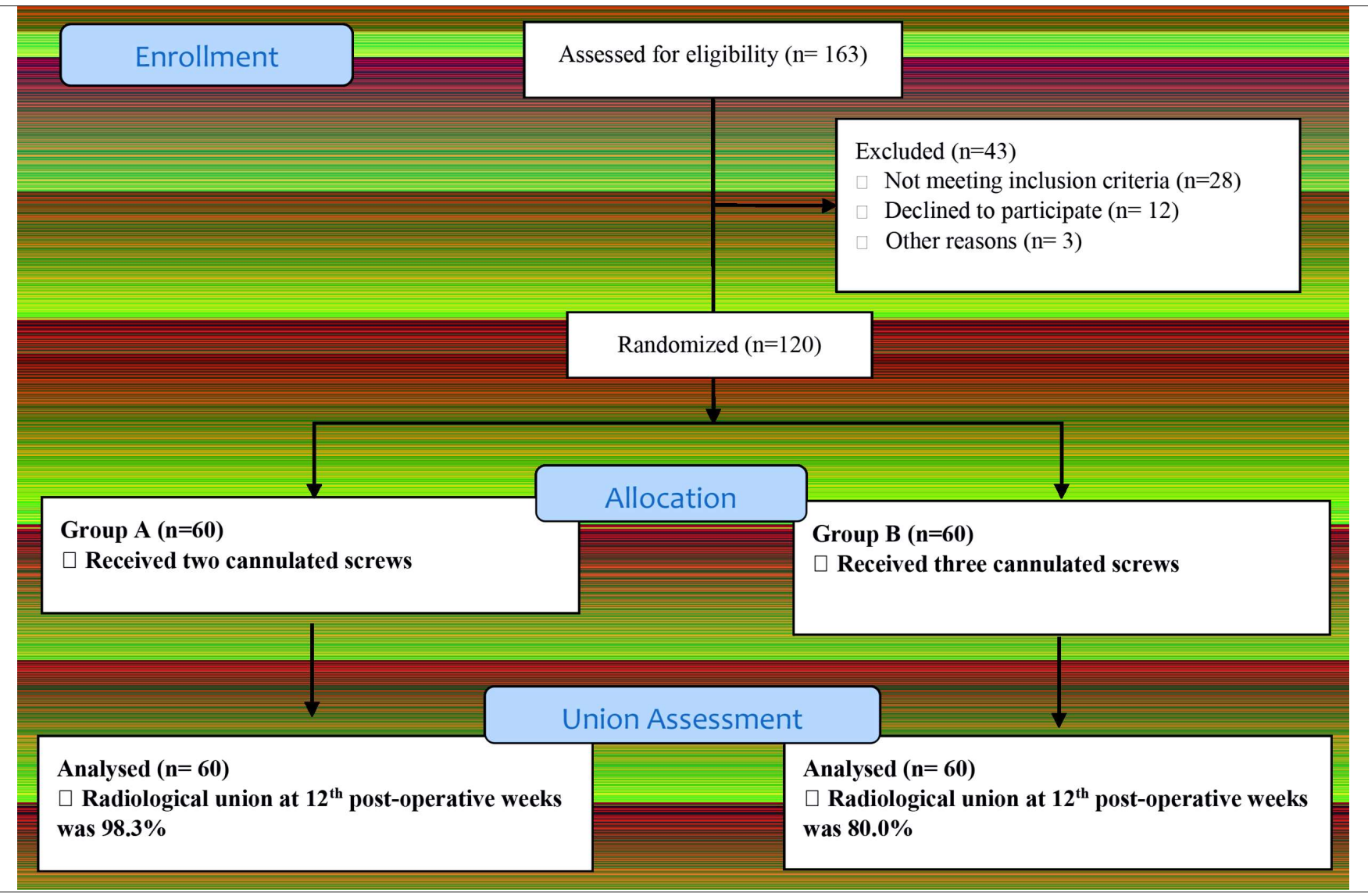

Figure 1: Consort flow diagram: Lesser the number of screws, greater are the chances of union: A comparison of radiological outcome of fracture of neck-offemur treated with two versus three cannulated screws fixation in young adults.

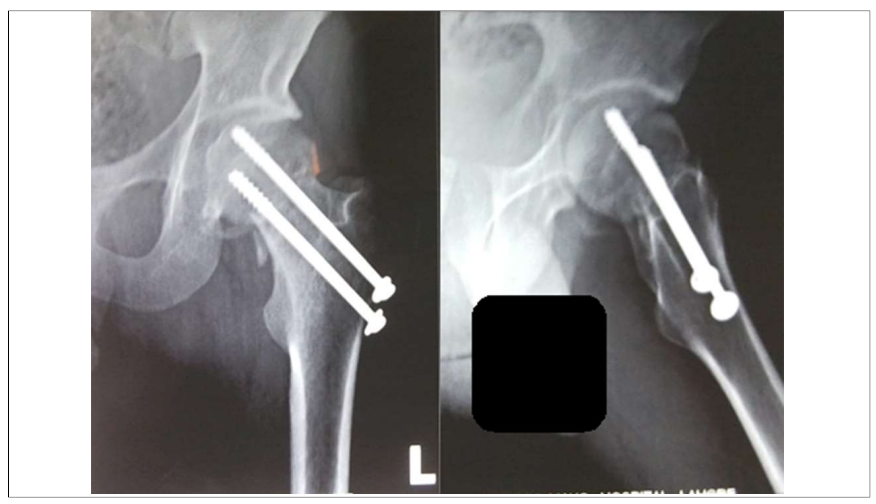

Figure 2: A radiography of patient with Garden type III fracture of left neckof-femur treated with two cannulated screws

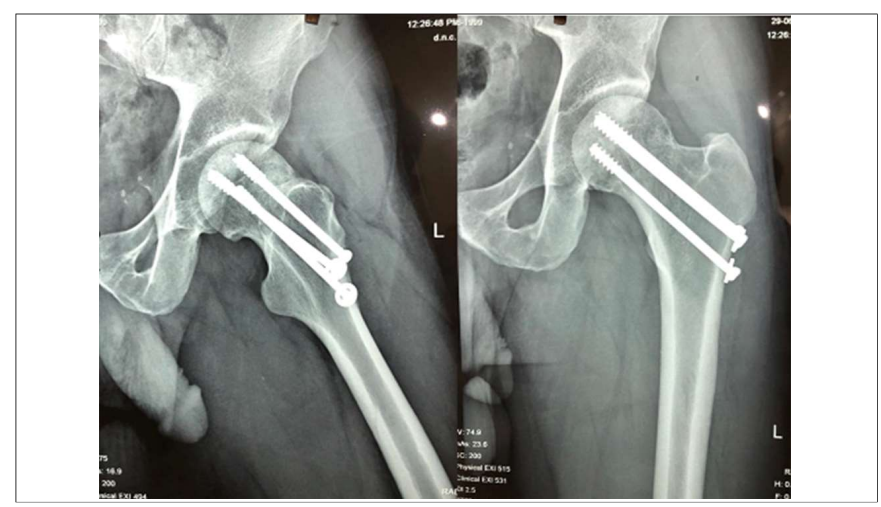

Figure 3: A radiography of patient with Garden type IV fracture of left neckof-femur treated with three cannulated screws 


\section{DISCUSSION}

Fractures of neck-of-femur in younger patients are usually a result of high-energy trauma, which are rare and more common in men than women. These fractures are internally fixed in younger patients when compared in patients with older age; and low physical demand they are fixed with primary hemi-arthroplasty. Avascular necrosis of femoral head is a common complication that can occur due to disruption of blood supply. Therefore, emergency fracture reduction is mandatory to reduce the risk of avascular necrosis. The gold standard is internal fixation through cannulated screws. ${ }^{3}$

For the fixation of femoral neck fractures, cannulated screws are now used universally as they provide better fixation than pin. Pins are associated with a noticeably high rate of non-union and infection when compared with sliding plate. When directly compared to the screws, no advantage was shown for an implant with a side plate. 10,11

Though there appears to be no clinical evidence indicating which design of screws is preferable, or if two, three or more screws are the best, biomechanical studies in cadavers ${ }^{12}$ or using bone models ${ }^{13}$ favour the application of three screws in a triangular fashion. On clinical grounds, Parker and Blundell14 meta analysed 25 randomised trials including 4,925 patients; and found it impossible to determine the optimum number or type of screws. Walker et al. in 2007 in a biomechanical study showed that three cannulated screws were more stronger and resilient than two screws, but the difference was statistically insignificant $(p>0.05) .14$

In the current study, radiological union of two cannulated screws was compared with three cannulated screws. There was no radiological union of any case on followup at $3^{\text {rd }}$ and $6^{\text {th }}$ postoperative week. Eleven $(9.2 \%)$ patients showed radiological union on the $9^{\text {th }}$ postoperative week comprising of $8(13.3 \%)$ patients among Group A and $3(5 \%)$ patients among Group B. However, the difference was statistically insignificant $(p=.114)$.

On the $12^{\text {th }}$ postoperative week, radiological union was evident in $107(89.2 \%)$ patients. The frequency of radiological union at $12^{\text {th }}$ postoperative week was $98.3 \%$ in Group A, and $80.0 \%$ in Group B, whereas the difference was statistically significant $(p=.001)$. Our results match with those of Xarchas et al., 6 who showed the frequency of radiological union to be $100 \%$ with two cannulated screws; and Chen et al., 7 who reported $100 \%$ union with two cannulated screws and $89.29 \%$ with three cannulated screws.6,7 Similar results have been reported by Basile et al. in 2012 ( $82 \%$ versus 55\%; p>0.05) proposing two cannulated screws being better than three cannulated screws. ${ }^{15}$ However, no significant difference was reported by Jordan et al. in 2014 (77\% vs. $78 \%$; $=0.95) .{ }^{16}$ A possible explanation for this conflict may be the patients' age; where Jordan et al. included old patients (mean age $80 \pm 12.3$ years), and this study sample consisted of young adults (mean age $35.49 \pm 8.47$ years).

Though higher radiological union was observed at $9^{\text {th }}$ week with two screws $(13.3 \%$ vs. $5 \%$; $p=0.114)$, but the difference was insignificant, suggestive of no added benefit of two screws in early union. But at $12^{\text {th }}$ postoperative week, the results were clearly suggestive of increased frequency of union with two as compared to three screws $(98.3 \%$ vs. $80 \%$; $p=0.001)$.

Thus, the hypothesis established at the start of this study was well proved and frequency of radiological union of two cannulated screws fixation was found to be significantly higher than three cannulated screws fixation in young adults with fracture of neck-of-femur.

An important limitation of this study was that only radiological union was focused and other parameters, like patient comfort/pain and functional outcome, have not been assessed. Moreover, this study only assessed early outcome; and patients were not followed further to see frequency of avascular necrosis, which was very important aspect of management of fracture of neck-offemur. It was, therefore, advisable to have a long-term follow-up, including other parameters, to find out more suitable surgical options.

\section{CONCLUSION}

Frequency of radiological union of two cannulated screws fixation was found to be significantly higher than three cannulated screws fixation in adults with fracture of neck-of-femur. Therefore, it is advisable to fix the fractures of neck-of-femur with two cannulated screws in adults.

\section{ETHICAL APPROVAL:}

The ethical approval was obtained from the College of Physicians and Surgeons Pakistan prior to commencement of this research.

\section{PATIENTS' CONSENT:}

Informed written consents were obtained from all the patients participated in this study.

\section{CONFLICT OF INTEREST:}

Authors declared no conflict of interest.

\section{AUTHORS' CONTRIBUTION:}

MUK: Made substantial contributions to the conception or design of the idea or the acquisition; drafted the work. MW: Drafted the work, data analysis.

MA: Data interpretation, helped in writing the manuscript. RDN: Revised it critically for important intellectual content; approved the final version to be published.

MBJ: Drafted the work or data analysis, helped in writing the manuscript. 
SFUHSG: Made substantial contributions to the analysis, or interpretation of data for the work; critically revised it for important intellectual content; approved final version to be published

\section{REFERENCES}

1. Cooper C, Campion G, Melton LJ. 3rd hip fractures in the elderly: A world-wide projection. Osteoporos Int 1992; 2:285-9.

2. Tidermark J, Ponzer S, Svensson O, Soder-qvist A, Tornkvist H. Internal fixation compared with total hip replacement for displaced femoral neck fractures in the elderly: A randomised, controlled trial. J Bone Joint Surg Br 2003; 85:380-8.

3. Ly TV, Swiontkowski MF. Management of femoral neck fractures in young adults. Indian J Orthop 2008; 42:3-12.

4. Rupprecht $M$, Grossterlinden $L$, Ruecker $A H$, de Oliveira $A N$, Sellenschloh K, Nüchtern J, et al. A comparative biomechanical analysis of fixation devices for unstable femoral neck fractures: The Intertan versus cannulated screws or a dynamic hip screw. J Trauma 2011; 71:625-34.

5. Ly TV, Swiontkowski MF. Treatment of femoral neck fractures in young adults. Instr Course Lect 2009; 58:69-81.

6. Xarchas KC, Staikos CD, Pelekas S, Vogiatzaki T, Kazakos KJ, Verettas DA. Are two screws enough for fixation of femoral neck fractures? A case series and review of the literature. Open Orthop J 2007; 1:4-8.

7. Chen Z, Wang G, Lin J, Yang T, Fang Y, Liu L, et al. Efficacy comparison between dynamic hip screw combined with antirotation screw and cannulated screw in treating femoral neck fractures. Chinese J Reparative Reconst Surg 2011; 25:26-9.
8. Nizami MA, Ahmed F, Shah M, Khan TB. Fracture neck of femur treated with cannulated screws in middle aged patients. J Pak Orthop Assoc 2009; 21:45-51.

9. Chiavaras MM, Bains S, Choudur $\mathrm{H}$, Parasu N, Jacobson J, Ayeni $\mathrm{O}$, et al. The radiographic union score for hip (RUSH): The use of a checklist to evaluate hip fracture healing improves agreement between radiologists and orthopedic surgeons. Skeletal Radiol 2013; 42:1079-88.

10. Christie J, Howie $\mathrm{Cr}$, Armour PC. Fixation of displaced subcapital femoral fractures. Compression screw fixation versus double divergent pins. J Bone Joint Surg Br 1998; 70:199-201.

11. Parker MJ, Blundell C. Choice of implant for internal fixation of femoral neck fractures. Meta-analysis of 25 randomised trials including 4,925 patients. Acta Orthop Scand 1998; 69:138-43.

12. Walker E, Mukherjee DP, Ogden AL, Sadasivan KK, Albright JA. A biomechanical study of simulated femoral neck fracture fixation by cannulated screws: Effects of placement angle and number of screws. Am J Orthop 2007; 36:680-4.

13. Selvan VT, Oakley MJ, Rangan A, Al-Lami MK. Optimum configuration of cannulated hip screws for the fixation of intracapsular hip fractures: A biomechanical study. Injury 2004; 35:136-41.

14. Maurer SG, Wright KE, Kummer FJ, Zuckermann JD, Koval KJ. Two or three screws for fixation of femoral neck factures? Am J Orthop 2003; 32:438-42.

15. Basile R, Pepicelli GR, Takata ET. Osteosynthesis of femoral neck fractures: Two or three screws? Rev Bras Ortop 2012; 47:165-8.

16. Jordan RW, Smith NA, Dickenson E, Parsons H, Griffin X. Risk factors associated with the early failure of cannulated hip screws. Acta Orthop Belg 2014; 80:34-8. 